\title{
UN FRAGMENTO DE ESTRATIS
}

A new fragment by the comic poet Strattis which comes to us on the Berlin ms. of Photius' Lexicon published by Reitzenstein.

La intención de esta breve nota es llamar la atención sobre un fragmento del poeta cómico ateniense Estratis, omitido hasta ahora en las ediciones de este autor. Se trata de la cita transmitida por el manuscrito de Berlín del Léxico de Focio, publicado por Reitzenstein ', en los siguientes términos:

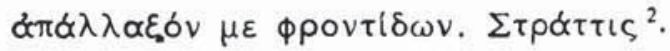

La razón de su falta en el corpus de Kock ${ }^{3}$ es obvia, dado que la edición de Reitzenstein es muy posterior. No se explica en cambio su ausencia en el Supplementum de Demiańczuk ${ }^{4}$ que sí recoge los otros fragmentos atribuidos a Estratis transmitidos por el manuscrito de Berlín ${ }^{5}$, omisión que es más extraña si tenemos en cuenta que la edición del Léxico de Focio de Reitzenstein viene provista de un índice de autores citados en el que no falta esta referencia.

Nada tiene sin embargo de sorprendente que no aparezca nuestra cita en la colección de fragmentos de Edmonds ${ }^{6}$, dada la total falta de pulcritud filológica que la caracteriza. Está claro que Edmonds se ha limitado a añadir los datos del Supplementum de Demiańczuk al corpus

1 R. Reitzenstein, Der Anfang des Lexicons des Photios, Leipzig-Berlín 1907. p. 155 , lín. 24.

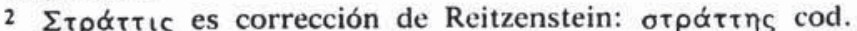

3 T. Kock, Comicorum Atticorum Fragmenta, Leipzig 1880, pp. 711-733.

4 J. Demiańczuk, Supplementum Comicum, Cracovia 1912 [Hildesheim 1967], pp. $288-290$.

5 Cf. Phot. p. 97, 21 (fr. 2); 92, 19 (fr. 6); 99, 12 (fr. 7); 120, 6 (fr. 8); 152, 4 (fr. 9).

6 J. M. Edmonds, The Fragments of Attic Comedy, Leiden 1957, pp. 812-837. 
de Kock, complementando el conjunto con abundantes correciones y añadidos producto de su fértil imaginación.

Omisiones como ésta ponen de manifiesto una vez más la urgente necesidad de acometer una edición de conjunto de los autores de la Comedia Ática, que incorpore los recientes testimonios papiráceos, excelentemente editados por Austin ${ }^{7}$, y que mejore las notorias deficiencias de la edición de Edmonds ${ }^{8}$. Sirvan estas líneas de modesta aportación de materiales para tal trabajo.

Alberto Bernabé y Ángela Ropero

7 C. Austin, Comicorum Graecorum fragmenta in papyris reperta, Berlín 1973.

8 En este sentido resulta esperanzadora la promesa de una nueva edición por parte de Austin y Kassel (cf. ZPE 14, 1974, p. 201, n. 1 y Austin, op. cit., pp. X-XI). 